\title{
Bypassing the Obvious: Implementing Cutting Edge Ideas for Futuring Urban Landscapes
}

\author{
Rob Roggema ${ }^{1,2}$ \\ ${ }^{1}$ Cittaideale, Office for Adaptive Design and Planning, Wageningen, the Netherlands \\ ${ }^{2}$ Institute for Culture and Society, Western Sydney University, Parramatta, Australia
}

\section{Email address:}

rob@cittaideale.eu

\section{To cite this article:}

Rob Roggema. Bypassing the Obvious: Implementing Cutting Edge Ideas for Futuring Urban Landscapes. Urban and Regional Planning. Vol. 6, No. 1, 2021, pp. 1-14. doi: 10.11648/j.urp.20210601.11

Received: December 17, 2020; Accepted: December 24, 2020; Published: January 12, 2021

\begin{abstract}
Vulnerable regions in particular especially face increased risks in periods of disruptive change. This mechanism is fed by a strongly felt uncertainty about the future, consisting of unprecedented events and is strengthened by an unshakeable faith in past approaches, reinforcing the problems. It is a common response to deal with these risks using traditional planning approaches. In other words, the problem here is that the current 'regime' (the set of policy responses) is embedded in the existing landscape of standards, habits, norms and approaches that lead to repetition of former solutions, which are often the obvious ones. This incrementality of the regime is in nature withstanding creative transformations. Unsafe planning is required to overcome a locked-in situation, especially in dynamic circumstances. The Toukomst Groningen project tries to escape this mechanism. In this article the crucial elements to achieve this are investigated and whether this is successful. In the Groningen region incremental planning has led to an increased vulnerability of population, nature and the land. People no longer trust their governments. In this article an alternative approach is investigated giving space to the most peripheric ideas in society, sublimating these into an overall 'mindblowmap' and implementing this long-term vision by executing a travelling circus, engaging the local residents in the realisation in order to rebuild local trust.
\end{abstract}

Keywords: Disruption, Incremental Planning, Transformation, Groningen, Future Visioning, Multi-layer Perspective, Regime Shift, Future Urban Landscape

\section{Introduction}

The Groningen province, in the north of the Netherlands is a culturally rich, spatial diverse and proud region. Historically it is a centre of public administration, culture, well established academic institutions, shipbuilding, advanced agricultural production technology and industry, and innovative architecture. The population is qualified as proud and stubborn, but honest and reliable.

\subsection{Transformability of Land-Use}

In recent times, this region is confronted with serious impacts of global and regional change, such as climate impacts [1], growth of urban population in vulnerable areas [2], food insecurity [3], pandemics [4] and the disruptive forces of local earthquakes resulting from decades of gas extractions in the area. Under these conditions, urban and land-use policies should support spatial adjustability. However, current land-use planning tends to be a muddling through process [5]. This can be illustrated by the fact that three consecutive land-use plans adopted for Groningen province limit transformation to approximately $2 \%$ of its uses [6], while the area that needs to be adjustable for the required adaptation to climate change [7] is estimated at $30 \%$ (figure 1 ).

\subsection{Subsection Impacts of Incremental Change}

In its very nature, incremental spatial policy is path dependent. In general, this means the solutions of the past are easily applied to the problems of the future. Over longer time periods this results in incrementally degrading land, a loss of spatial quality and increased vulnerability, because an unprecedented future is not taken into account in planning for this future. In disruptive times it is therefore potentially dangerous to continue muddling through [5]. When all incrementally adopted and well-meant policy decisions in Groningen are added together, the general 
quality of landscape, wellbeing and welfare decreased. Large parts of the landscape turned into a desert-like environment, while in other parts the soil shakes or salinates. Unavoidably, this led to a doomed degraded landscape (figure 2), which, to a large extent, has lost basic social, ecological and spatial qualities and where its population lost trust [8].

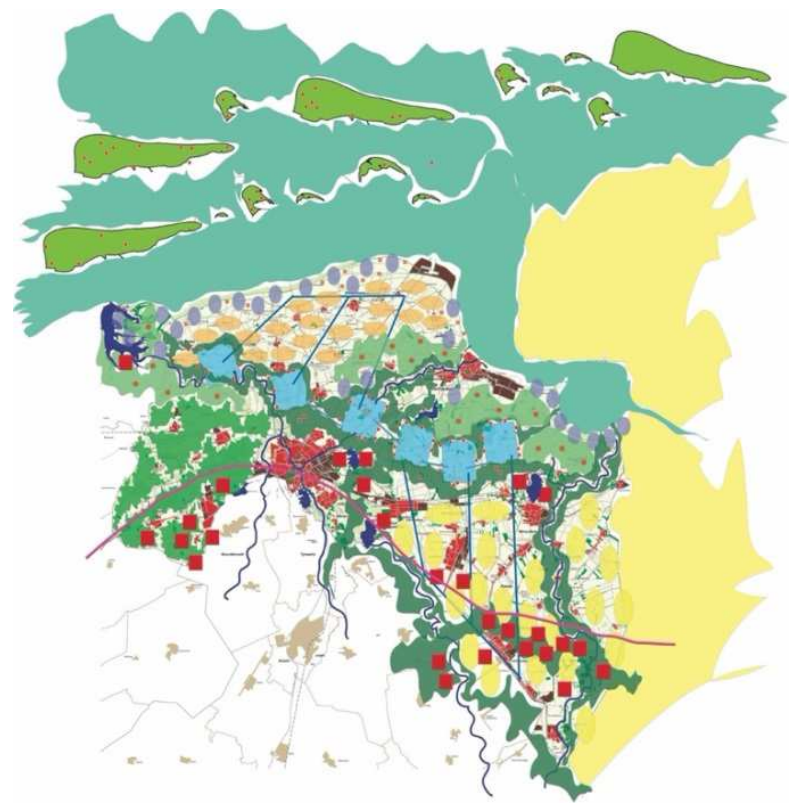

Figure 1. Plan for an optimally adapted Groningen [7].

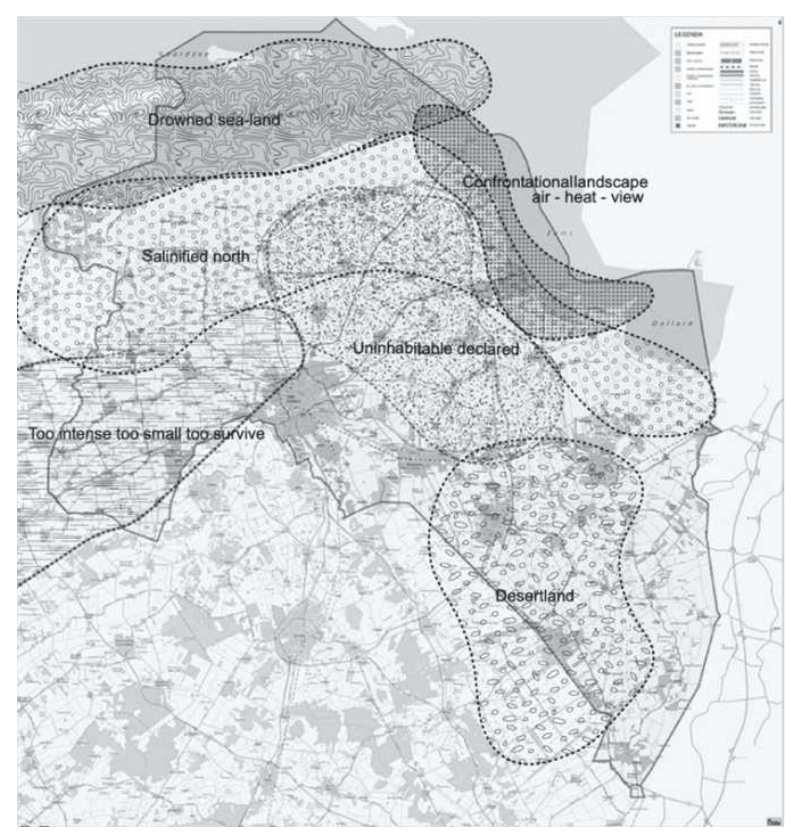

Figure 2. Result after decades of incremental best possible policy decisions [8].

\subsection{Beyond the Obvious}

Taking the perspective of the long-term, muddling through will not suffice. A creative, design-led process is needed, in which a positive future can be envisioned, and alternative projects are conceived as new points of departure towards a desirable future. By taking the peripheric ideas as the starting point of visioning it becomes possible to move beyond the obvious outcomes. In this research a structured way of allowing this to happen is proposed.

Firstly, the methodology used is described (section 2), after which current policies and public ideas are analysed (section 3 ). In section 4 a scoping of existing theories is presented and used to develop a framework for co-creative innovation and applied to the Toukomst Groningen project (section 5). Finally, conclusions are drawn, and a way forward proposed (section 6).

\section{Methodology}

The methodology (figure 3) consists of three overlapping stages: the analysis of current practice in the case study area, theoretical explorations to build a novel framework and the application of this framework in the case study area.

\subsection{Analysis}

1. Analysis of prevailing policy documents in Groningen province. Over 1000 policy measures extracted from 85 relevant spatial policy documents of municipalities, waterboards, and. the regional government have been identified and categorized. Firstly, it is determined if the measure can be qualified as a trend ${ }^{1}$, strategy ${ }^{2}$ or transformation $^{3}$. Secondly, of every measure is analyzed at which time horizon it aims at solving a problem: the short, middle or long term. Thirdly, how well each measure anticipates high risks and unprecedented change is estimated: the anticipation horizon.

2. Analysis of people's ideas. The 900 ideas that have been submitted by the Groningen population to the Toukomst website have been analyzed using the same categorization of time horizon and anticipating high risks and uncertainty.

3. Analytical conclusion: The outcomes of the two analyses are connected and a general conclusion is drawn. In particular, whether an alternative approach for dealing with uncertainty is required is concluded.

\subsection{Theory}

1. Scoping theories: in this step three relevant theories to be of use in such a wicked context are explored. The question is how to enhance the spatial transformations needed to anticipate future uncertainty and change and which theoretical approaches are suitable. The following theories have been surveyed and analyzed: Multi-level perspective, Collaborative learning and Transformation. Each of these have been in-depth investigated and suitable elements are derived for improving the transformability of land-use by overcoming incremental change.

2. Conceiving a framework: The elements deemed suitable,

1 Trend: a trend states which changes are expected on the short, middle or long-term

2 Strategy: a strategy aims to formulate an objective to respond to a certain trend

3 Transformation: a transformation proposes a tangible measure to realise a certain strategy 
derived from each of the theoretical bases are brought together and integrated in one framework for co-creative innovation. A framework that makes it possible to analyze a specific case study and position it in the framework, but also to derive novel insights that can be put to practice.

\subsection{Application}

1. Applying theories to Toukomst: each of the theories are used to understand the current mechanisms of the Groningen region and the Toukomst project. The insights of formulating the case study aspects within the three theoretical frames improves the potential ways forward.

2. Creation of the Toukomst framework: When the theoretical applications are brought together in the framework the way the current process and barriers to change work in practice, is analyzed and gives rise to novel interventions in the framework. These novelties are identified as potential bifurcation point, where existing approaches should be changed in order to increase transformability.

3. Designing so-called 'carouselements': after understanding where these novel interventions should appear, specific ways are investigated. Which are the creative jumps that can be enhanced, how could co-creativity support these jumps and what is the created value of these creative jumps, are the questions that guide towards developing the novel approaches required. As these creative elements are interdependent and follow from each other they are seen as a carousel, continuously interacting.

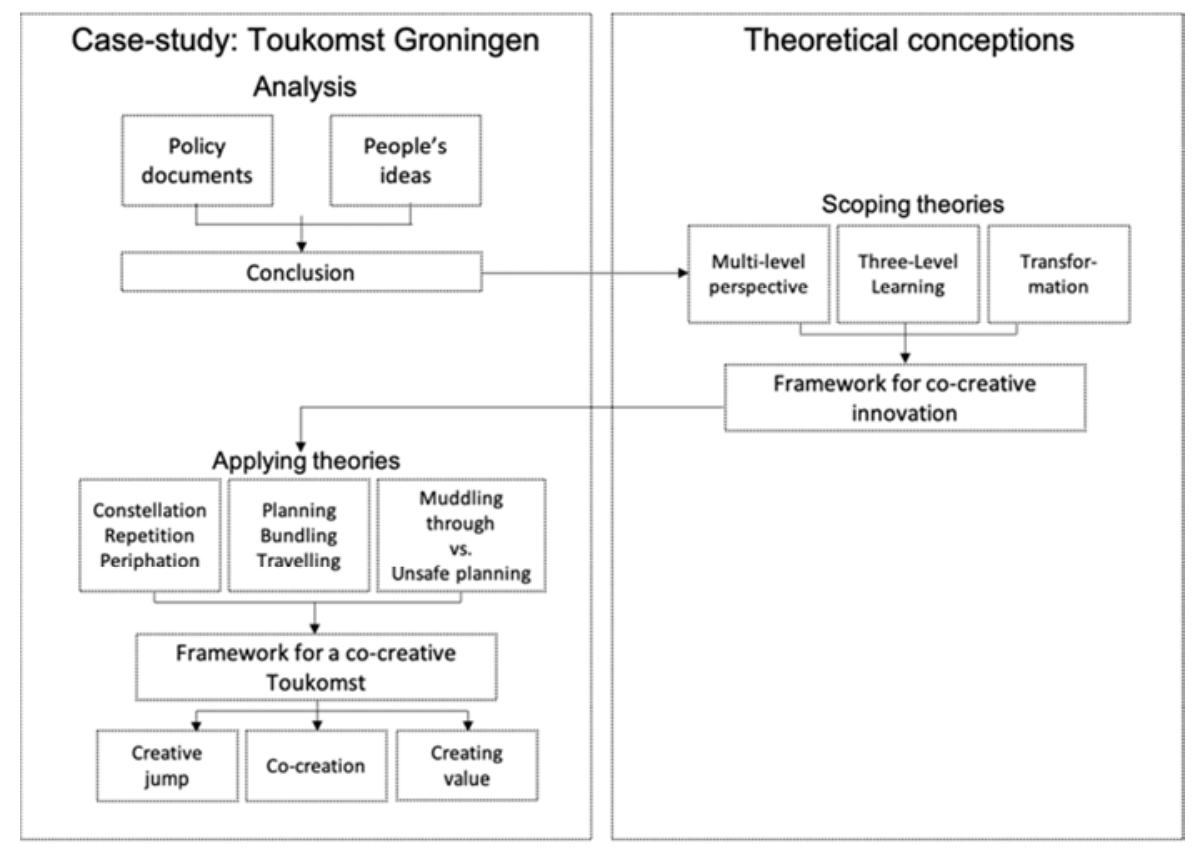

Figure 3. Methodology.

\section{Toukomst, the Analysis}

\subsection{Future for Groningen}

In Groningen, a province in northern Netherlands, an abundance of policy documents is written, negotiated and adopted by municipalities, water boards and the regional government. Observing the currently prevailing 85 policy documents an image of ostensibility appears. The future is dealt with reasonably and every possible disruption is taken into account, analysed and treated with appropriate measures. However, this has not led to an increased trust in regional governance. The opposite occurred. This is caused by a long history of being treated as a colony, where natural resources were depleted. Peat was excavated and shipped, straw was used to fabricate cardboard boxes and salt is mined for high-tech industries. The fertility of the soil is withdrawn for growing sugar beet, grain or potato.

The high mass of extracting had yet to come when natural gas was discovered in the early 1960s. between 2012 and 2020 , as a result of this, a series of earthquakes have occurred in the area, eventually leading to a serious decrease of trust in the government emerged. After a period of ignoring, denial and downplaying the concerns of the population, the national and regional government have admitted a fundamental policy shift is required to rebuild homes but also to rebuild trust. This has led to the Toukomst project, which is the local dialect for the word Future. The objective here is to generate 'superb' ideas proposed by the local people, in the hope these ideas start a mechanism of rebuilding confidence in government.

\subsection{Analysis of Policy Plans}

In current policy plans more than 1000 policy measures are formulated. Each and every one of these have been qualified as a trend, strategy or transformation and subsequently been put on two horizons. The time horizon determines their short (0-5 years), middle (5-20 years) or long (20-50 years) focus. The anticipation horizon determines their capability to deal 
with uncertainty and high-risk futures. Measures are characterised whether they can deal with well understood problems (known knowns; certainty), problems we are conscious of but do not understand (known unknowns; uncertainty) and problems we are not aware of (unknown unknowns; deep uncertainty).

All measures can be located in a diagram (figure 4), which shows whether measures are in majority anticipating uncertainties on the long term or not. The analysis for Groningen policy reveals that by far most trends, strategies and transformations (figure 5) focus on the shorter term and on well understood futures. This reinforces the observations of muddling through planning processes: it is easier to suggest policies in a continuous process of defining the largest possible small step, that respond to specific, predictable problems and can be realised quickly and visible for the people. This incrementality advantages measures that are familiar or have been applied before.

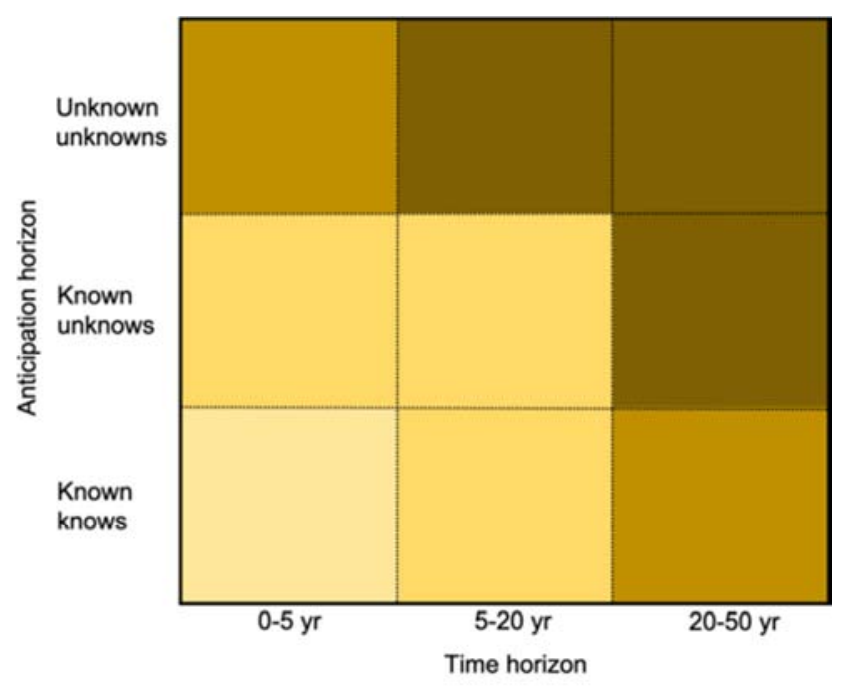

Figure 4. Diagram of time and anticipation horizons.
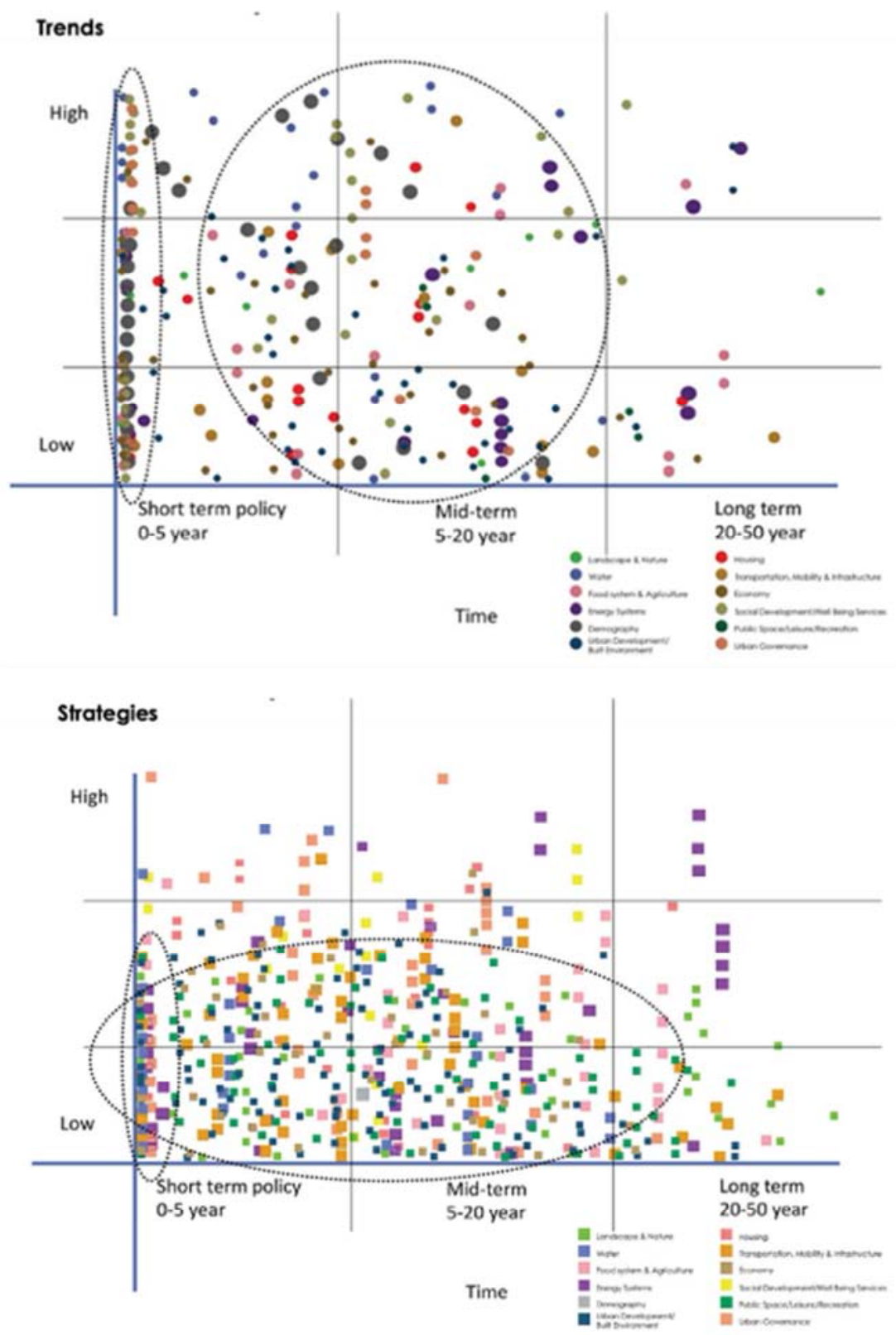


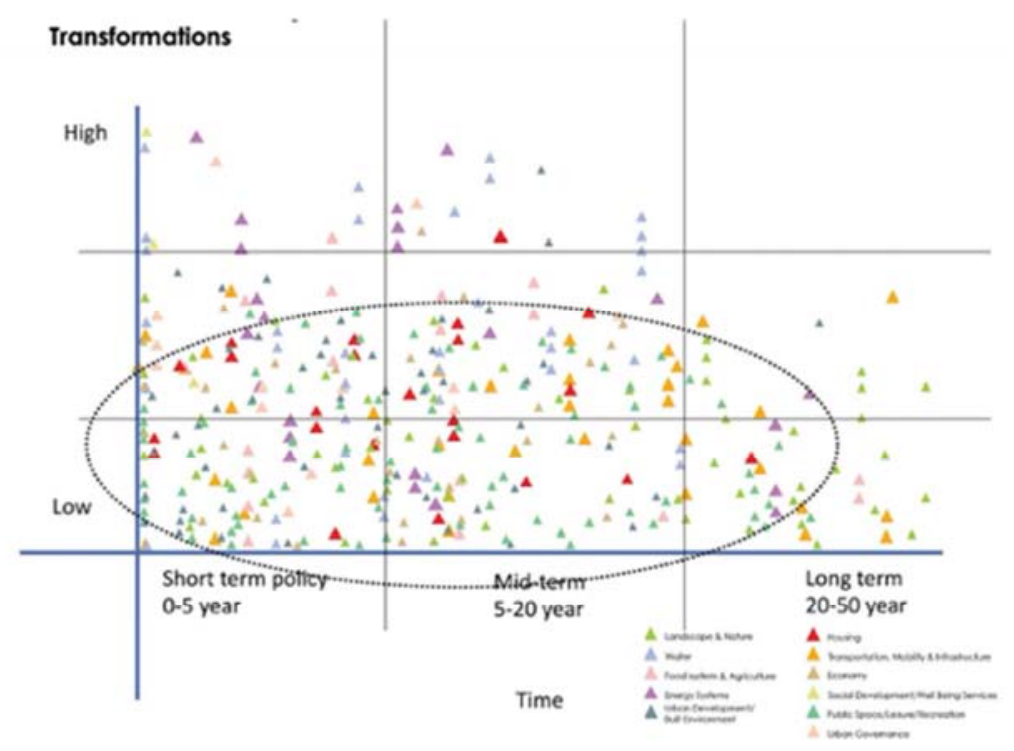

Figure 5. Locating all trends (top), strategies (middle) and transformations (bottom) in the diagram [8].

The inability of policymaking to focus on the long-term, deep uncertain futures explains also why it proves to be difficult to mainstream climate change in spatial planning. The small policy changes are able to solve small individual problems but are impotent to developing a coherent long-term perspective. There is no vision of the future [9].

\subsection{Analysis of People's Ideas}

The quest for superb ideas is therefore paved with pitfalls. A superb idea envisions a future beyond the current time horizon, transcend local or individual interests and contributes to the quality of life even if the future is unknown. Analysis of the 900 submitted ideas reveal a similar focus on the short term and well understood problems (figure 6). A mere 20 extravagant ideas could be identified that are truly innovative, attractive and imaginative, being, potentially, superb.

In conclusion, the analyses illustrate that both policy measures and local ideas suffer from the 'muddling through syndrome', being incapable of looking at complex problems that are deeply uncertain only showing their impacts long after present times. This practice is deeply rooted in our western way of planning for the future and gives rise to serious concerns as society will be confronted with unprecedented global and regional change. As mentioned above, the transformability of land-use should therefore be enhanced dramatically, and this requires novel spatial planning approaches paving the way for an alternative planning practice.

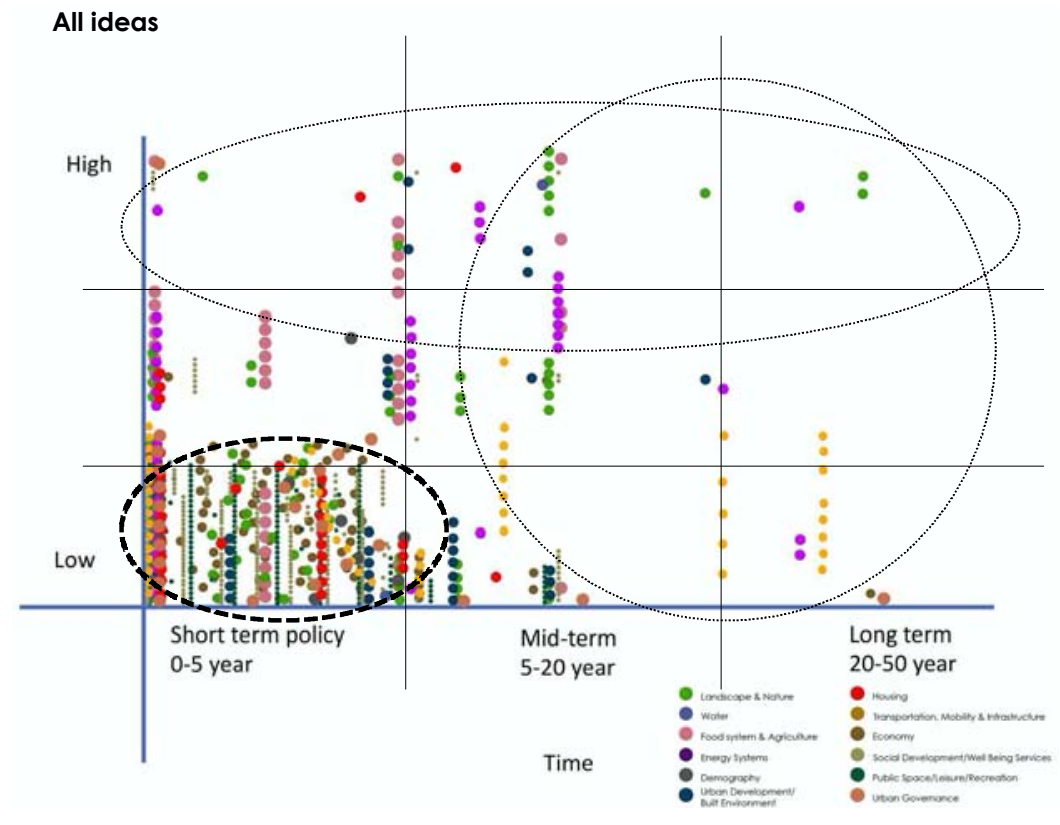

Figure 6. Swarm image of 900 future ideas. 


\section{Towards a Framework for Co-creative Innovation}

Cities, regions and landscapes are no longer seen as static, the notion of equilibrium has been replaced by a veritable potpourri of chaos, catastrophes and bifurcations [10]. An illusionistic view on ever stable urban and rural systems could end in a hard confrontation with rapid, unprecedented changes, which are already witnessed and occurring at an increased level. Thinking in dynamic change is therefore a prerequisite that starts with formulating a desired future state (system B) rather than a slight modified version of the current state (system A). Because it is intrinsically impossible to become B when starting from system A, the starting point of spatial transformations is found in a predecessor of the desired new system B: defined as B-minus [11].

Current spatial planning policy and practice is unsuitable of adopting this fundamental shift because the very essence of transformation is to step away from the widespread code of what is unconsciously accepted as 'good planning', positioning 'the planner as the one who knows' [12]. An alternative 'unsafe' planning approach anticipates uncertainties and disruptions, and abandons tightening and dictating regulations [13]. When the 'non-innovative state of mono-rationality' is replaced by an 'unsafe' planning practice of poly-rationality, liquid, turbulent or wild boundaries of both planning thought and spatial territory occurs. This planning practice embraces deep uncertainty about the future, accommodates differences and encourages the new and creative. It literally 'plans without the safety of a condom' [13]! Insurgent planning of South-African slums [14] can be seen as a way of bringing actors from outside the normal governmental planning arena 'inward' [15], emphasising the power of self-organising groups, allowing them to create a disordered order of spaces without being led from the traditional governmental or political arena [16]. This way urban environments and spaces are 'becoming' rather than being planned from the top downward. The assumption being that these approaches accommodate disruptive and unprecedented change, exactly the task current planning policies are facing.

Three theoretical foundations are selected to understand and potentially support transformational, unsafe, planning approaches.

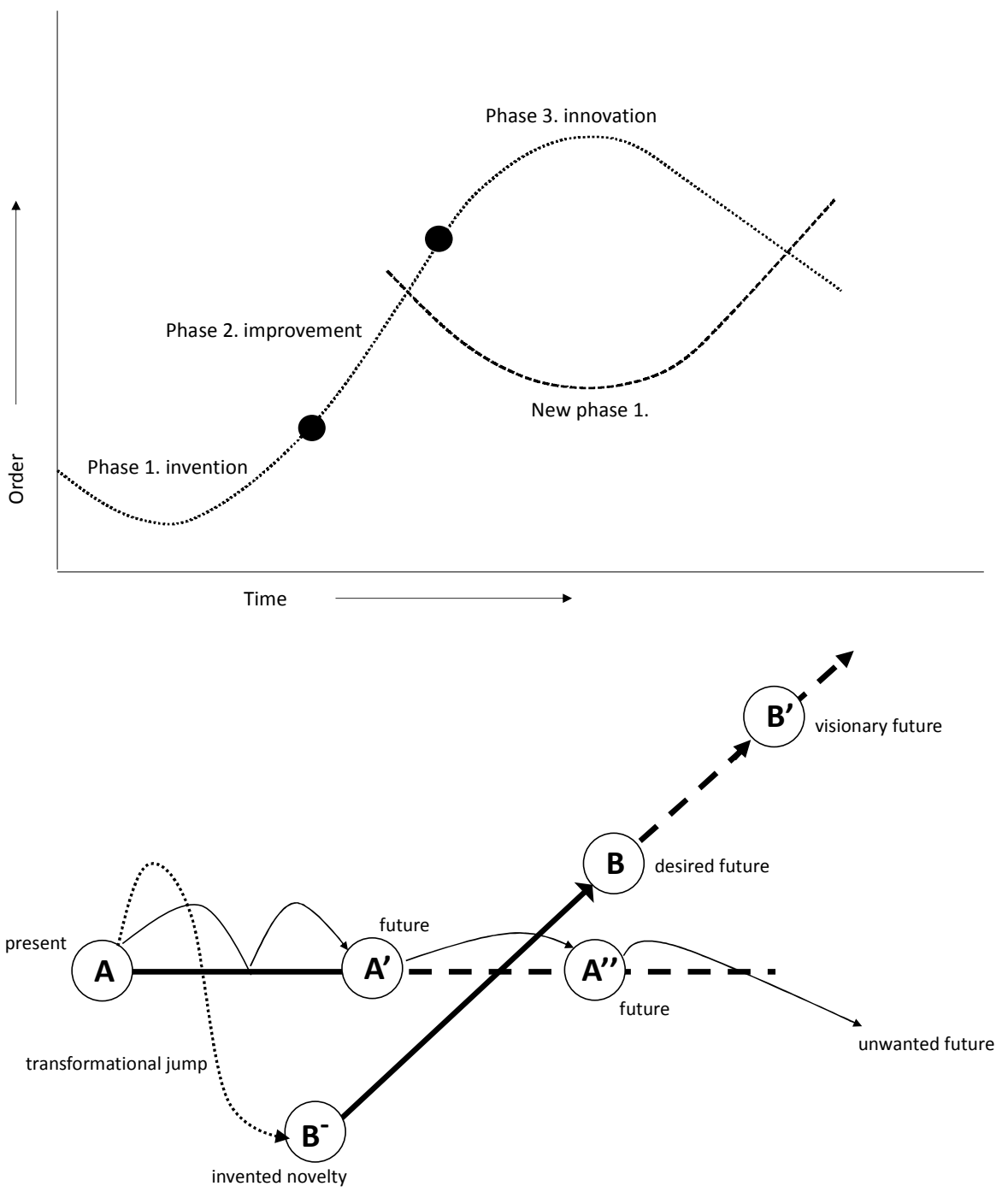

Figure 7. Transformational process [22] (top) and a transformational jump from existing pathway A towards new system B [11] (bottom). 


\subsection{Transformational Processes}

Transformation trajectories [17-19] are described as 'the capacity to transform the stability landscape itself in order to become a different kind of system, to create a fundamentally new system when ecological, economic, or social structures make the existing system untenable' [20] or as 'disconnected processes of growth' $[21,22]$. The disconnection (or the need to come loose of the original system (A), is represented as starting of the next 'forming' cycle (phase 1) while the previous 'integrating' stage (phase 3) is still ongoing (figure 7, top).

Transformational processes aiming to establish a novel system (B) will never reach that state when embarking on a system A-trajectory. This implicitly will bring the system no further than undergoing slight changes turning into a renewed version of this system, being A-dash, or A-double dash [11]. In order to enhance the transformational jump, niche conditions for B-minus novelties allow for the novel system to take off and start the pathway to the desired change (figure 7, bottom).

\subsection{Multi-level Perspective}

The transformational jump from an existing pathway A onto a new trajectory $\mathrm{B}$ can only start when niche innovations (B-minuses) are actively recognized, embraced and stimulated. The multi-level perspective [23-25] describes these changes starting in the locus of radical innovations where novel configurations appear. These are capable of interfering with and influencing established practices and associated rules that normally stabilise existing, socio-technical, regimes. Once these regimes have undergone a change, the exogenous socio-technical landscape, representing the nearly unchangeable values and biophysical features might transform, if at all (figure 8).

When the desire for a new future system emerges the tension with the existing regime is profound. This window of opportunity only appears when the right niches are created, within which ideas are reinforced, becoming the dominant design and growing strong enough to eventually break through the current regime forming a new, dynamically stable, one.

The effectiveness of the innovation e.g. whether a novelty fails, modifies the regime or is capable of transforming the landscape, is determined by the strengths of the reinforcements at these levels $[25,26]$. It seems obvious that a system that is better at enforcing changes, is also more capable of dealing with unprecedented changes or disruptions. However, the tension between the existing regime, reinforced by the unchangeable values and biophysical features of the landscape and the necessity to fundamentally change and disrupt the current regime, is a battlefield between continuation of system A vs transformation to system B. Additionally, the likeliness of a transformative jump being successful is influenced by the environment within which this happens.

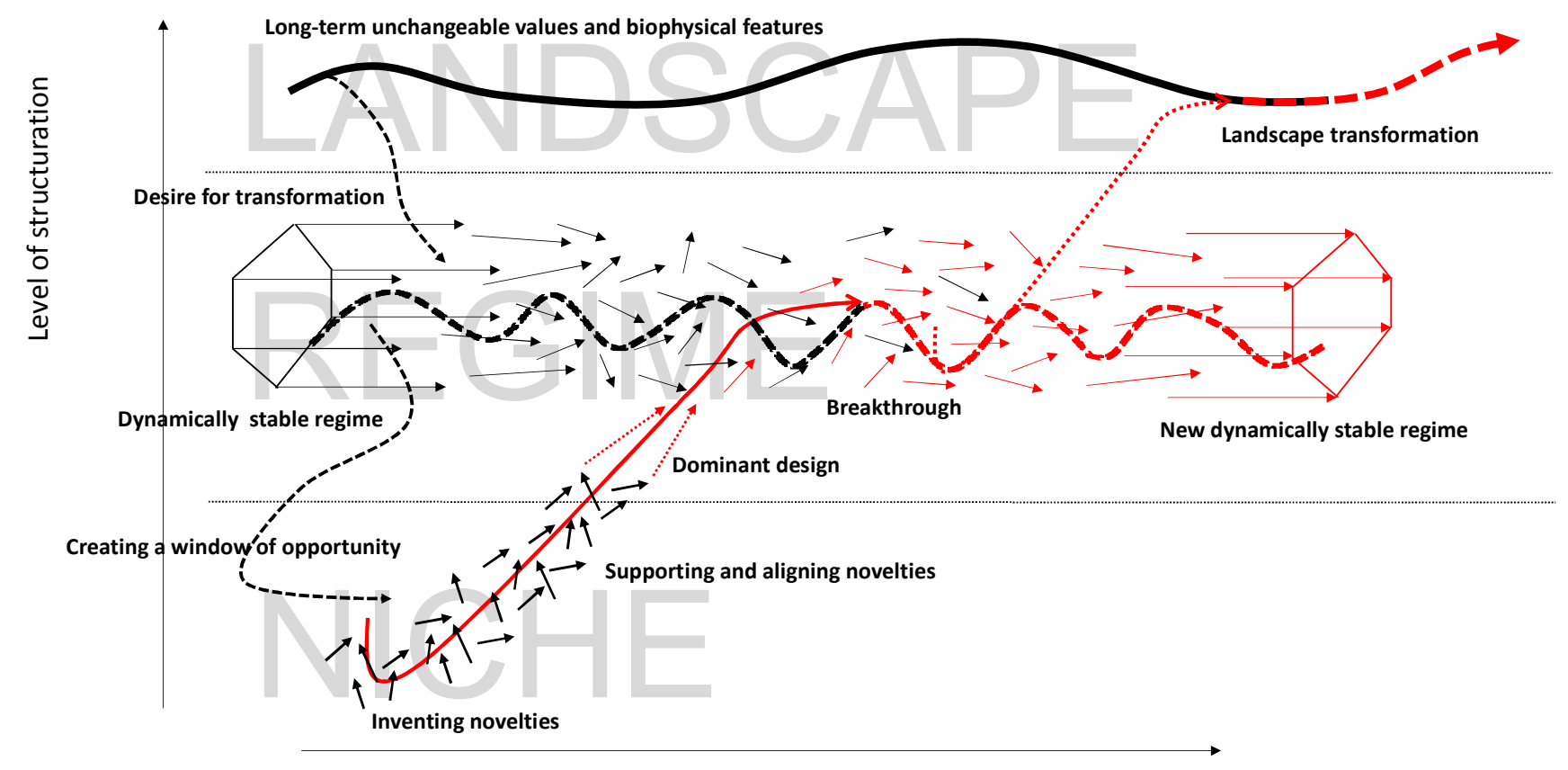

Time

Figure 8. Regime shift under influence of niche innovations (adapted from [23]).

Different pathways (transformation, reconfiguration, technological substitution, and de- and re-alignment) are possible, depending on the readiness of niche developments, the magnitude of the landscape change and the susceptibility of the regime actors [27]. In summary, the timing of landscape pressure and niche development determines the type of pathway. Long-term unprecedented problems implicitly challenge the existing landscape. Whether niche developments are ready enough de- and re-alignment may occur of can be (technical) substituted. A high level of landscape pressure and a high readiness of niche developments create the environment for a transformative 
development as described in section 4.1. In this context hidden novelties [28], or B-minuses [11] can be brought to fruition, are ready to break through existing conventions and substitute the current regime.

\subsection{Third Level Learning}

When current, path-dependent planning, often dealt with by 'muddling through', and transformative, disruptive pathways, suited by unsafe planning, meet, the highest level of learning in an emergent self-organising process is needed. In this context, it is simply not satisfying to transfer information as an instructor, to be an expert, or to build skills and competencies focusing on the learner (figure 9). Shifting mental models and knowledge creation are required, which are oriented towards teams, partnerships, and community collaboratives [29].

Collaborative Learning Technologies are useful here, which are based on the assumption that relevant knowledge is present in all members of the learning environment. There is no single right answer, no differentiation between 'experts' and 'non-experts'. Furthermore, knowledge is created collaboratively, characterised by self-organising processes encompassing multiple connections and interactions between all group members. In this collaborative learning environment, the new inventions emerge most easily. Collaborative learning interventions aim at the highest level of learning complexity, or transformational learning [30], and are capable of creating novel solutions to 'adaptive' problems. New shared views emerge, and unprecedented mental models are created, serving as more effective Theories-of-Action [31-33]. In addition, interventions in this collaborative learning realm are inherently cyclical and non-linear in nature, using self-organising processes to create constantly new responses to changing situations.

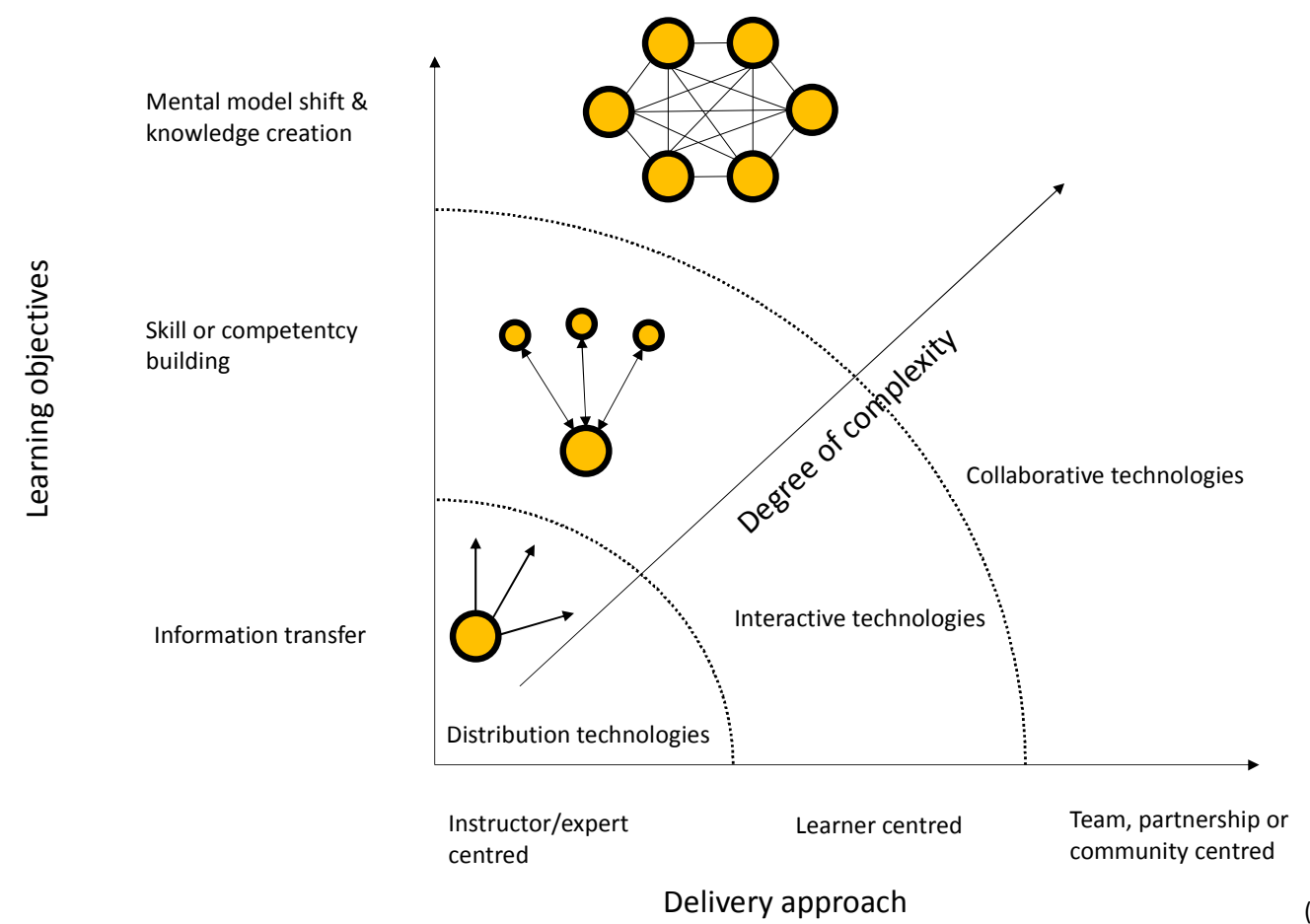

Figure 9. Learning at three levels [29].

\subsection{Integration: Towards a Co-creative Innovation Framework}

These three theoretical foundations are connected to one framework for co-creative innovation (figure 10). The multilevel perspective, depicting the landscape, regime and niche levels, is taken as the basis for the framework. When this is combined with the three learning levels (instruction, individual learning and collaborative learning), linkages become visible. At the landscape level all three learning types appear, from well-established instructions, interactive learning of tutor-student relationships and team learning. At regime level, advanced forms of learning are applicable, while at niche level collaborative forms of learning are working at its best, because novelties can only be invented when unprecedented interaction occurs between multiple actors.

The third addition is the principle of transformative change. All systems evolve and undergo transformation. 'Born' in a collaborative learning context at niche level, a niche-novelty matures and is capable to replace existing elements at the regime level, eventually becoming the new regime. Naturally, this system evolves and becomes an established 'landscape'. Over time, tensions and cracks in the once innovative system will occur, placing this system at risk of malfunctioning and decline. However, before this is about to happen, an alternative system is getting ready to replace the former. New novelties (B-minuses), at their turn 'born' in a collaborative learning environment at niche level, become attractors for components of the existing system, allowing them to make the jump to the new reality. In order to allow this to happen, the learning conditions at niche level must be created to develop 
novelties and allowing them to mature. Therefore, a cyclic and iterative process of creation is needed.

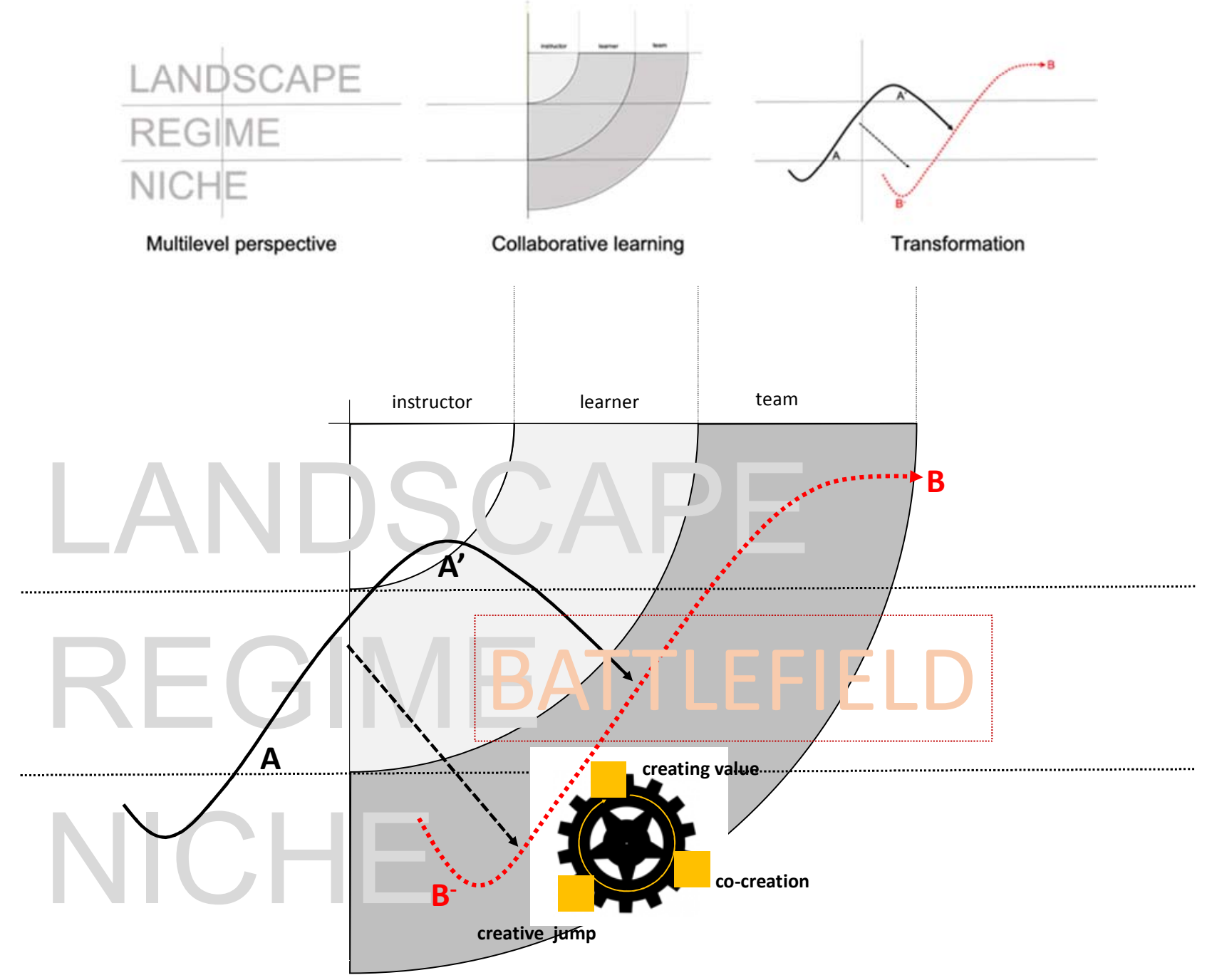

Figure 10. Framework for co-creative innovation.

This iterative process of creation operates at niche level is supportive of the creative jump from system A (in black) to B-minus (in red). Here, team learning is imperative to achieving a successful outcome. This transformative carousel consists of three 'carouselements':

1. Creative jumps must bring together the most creative experts in thinking 'beyond the ordinary'. This is a necessary step to find novel solutions not hindered by the regular and well-known solutions for day-to-day problems.

2. Co-creation of extraordinary concepts and ideas in a process driven by all members of the learning environment. Unique concepts stimulate people to think beyond the normal hence collaboratively find solutions that respond to the unknown problems in the area. In a transparent and inviting atmosphere, fluidity of thinking occurs, and everyone's insights and understanding lead to unexpected outputs.

3. Creating value occurs when novel solutions are seen as acceptable and implementable. The involvement in such a co-creative process creates a strong ownership of the solutions created. The brainchildren of these solutions will defend the outcomes and spread the word, implying value is created and a growing network of people will be supportive. From its niche environment the 'carrousel' interferes in the regime level, where it aims to break through existing conventions. The carousel exists as long as necessary to iteratively cross-fertilizes creative jumps and co-creative processes, creating the value to accelerate the uptake of novelties at regime level.

\section{Toukomst: The Application}

Obvious solutions will not suit disruptive and unprecedented changes. Generally, these only copy well-known solutions of the past, which at the time were meant to solve less disruptive changes. The theoretical framework for co-creative offers a way to understand the current barriers for change and its limitations to think beyond the obvious propositions, and also provides ways to create a creative environment within which novel solutions can be generated. 


\subsection{Current Framework}

Looking at the Multilevel Perspective of Groningen (figure 11), at the landscape level an existing constellation is found of a regional government, which, in conjunction with local agencies, determines major spatial policies. These organizations have a long history of policy- and decision making, forming the long-term planning context. At this level learning is instructive and planned. Formal roles of governmental entities determine which role others are expected to play. This environment involuntarily guides planning practice at regime level. Planning processes are often repetitive and the engagement, with the best intentions, is following well-known pathways. The learning type is driven by the interaction between the 'teacher' (the government) and the learner (the people), expressed in a guided open process in which the residents submit their ideas then bundle these in larger projects. This is typical second level learning. The niche environment can only be revealed when the current regime is abandoned in search of real peripheral solutions and ideas. Therefore, third level learning is required in which the journey can be experienced as a team, travelling without a specific end in mind.

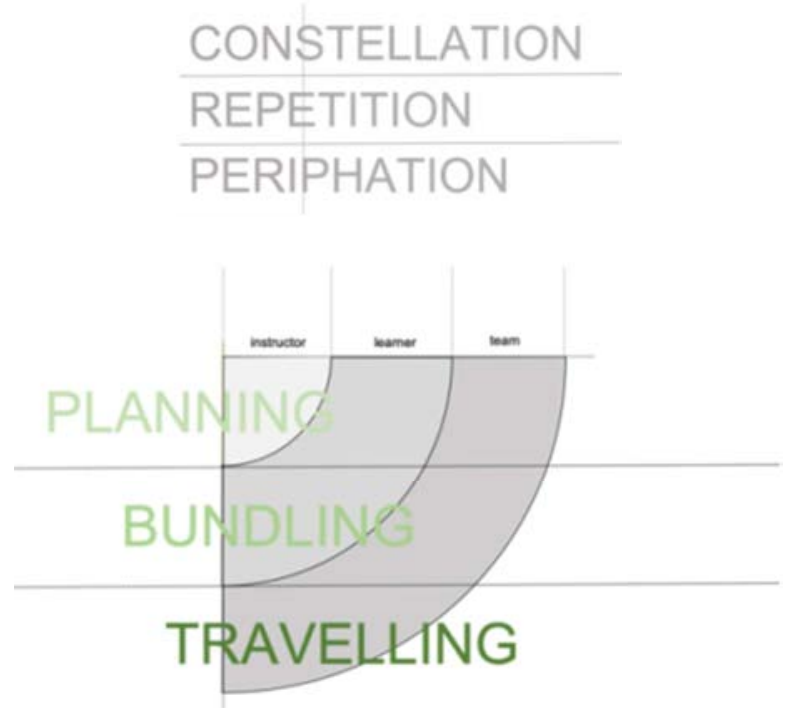

Figure 11. Multilevel Perspective and Three Level Learning in the Groningen context.

The transformational jump takes place at this level. Where the current regime reinforces short term solutions that are proposed for the known knowns, the locus of policies and people's ideas, the novelties can be found at the periphery (figure 12). The move (or jump) brings the system from the regime level, by active search for these peripheric solutions to the niche level (figure 13). Here the build-up of a novel system starts. Given the unknown unknows of the near future a form of unsafe planning must be adopted making the search for these novelties possible. This implies taking the risk of no longer muddling through [5] but planning without a condom [13]. Real superb ideas can only become reality by allowing radical experiments.

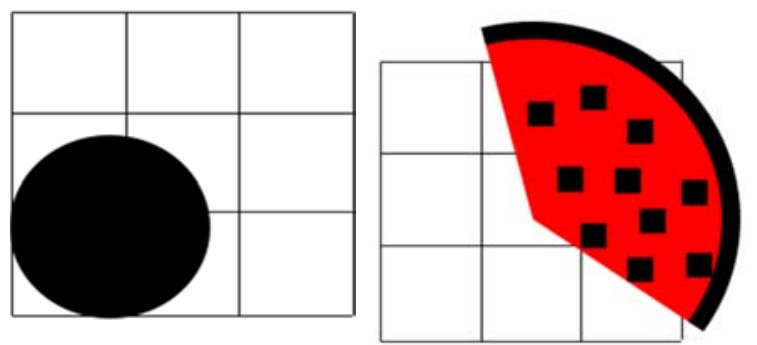

Figure 12. Short term and well-known vs peripheric.

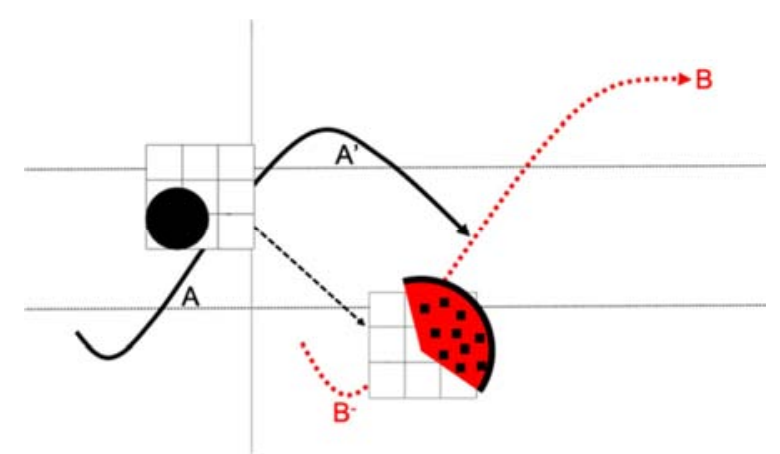

Figure 13. Transformative change.

\subsection{Carouselements}

The locus of radical novelties is outside the current regime and team learning prevails here in order to give space to unpredictable interactions that lead to novel solutions. Exactly what is needed. Here, the co-creative environment consists of enabling a creative jump, arranging co-creativity and (re)creating value (figure 14). These three carouselements operate simultaneously, strengthening each other in no particular sequence, and are mutually dependent.
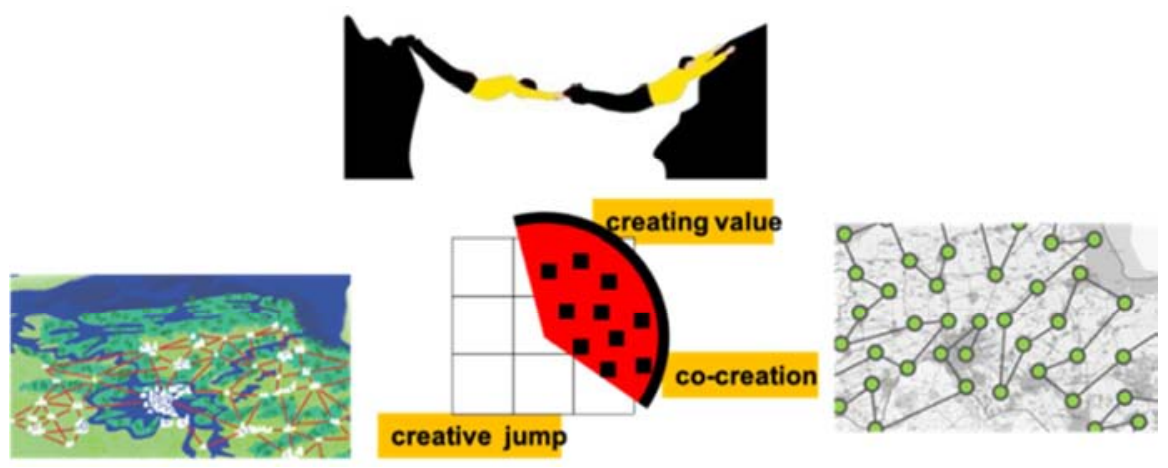

Figure 14. Carouselements. 


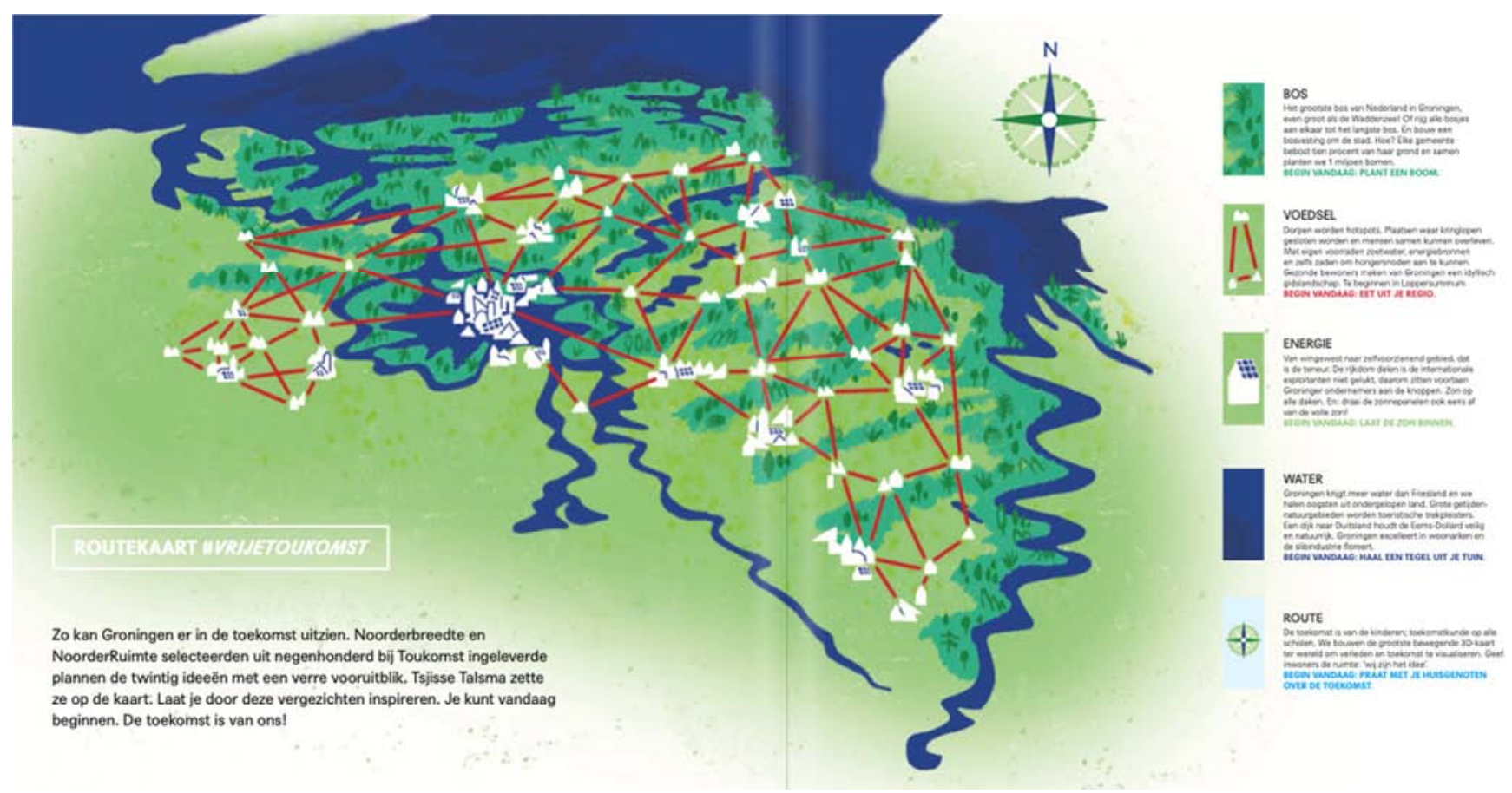

Figure 15. The 'mindblowmap' of Groningen (image credit: Tsjisse Talma [34]).

\subsubsection{Beyond the Obvious I}

By selecting the most peripheric ideas out of the $900^{4}$ that were analysed and sublimate these into one overall image, a so-called 'mindblowmap' (figure 15) a future can be imagined that lies outside the usual frame. This is represented in the form of a large scale, abstract visualisation of the long-term future. At first sight, these peripheric ideas seem unrealistic and will encounter serious objections. However, by integrating these ideas a novel future that meets the requirements to respond to deep uncertainty a plausible future can be sketched which can become acceptable for the current stable regime. This gives decisionmakers confidence to pursue this integrated future-oriented approach.

\subsubsection{Beyond the Obvious II}

The 'beyond the obvious', peripheric ideas may enforce real depth in collaboration and are capable to enhance community cohesion. Though these peripherical ideas are fed by long term developments and acknowledge uncertainties, by definition they do not satisfy political or societal short-term desires. This poses a risk on the acceptance of the content, as they disrupt the current regime of accepted, habits, and prevailing codes and standards. The extraordinary ideas do not create a novel future by just being extraordinary. For achieving this an innovative and inspirational process is required. In the Toukomst context a novel process has therefore been invented. Through a 'travelling circus', local residents are engaged on a permanent basis for a prolonged period of, at least, 10 years. This circus is

4 'Endless Forest' (https://www.toukomst.nl/ideeen/het-langste-bos-van-nederland/), 'Loppersummum' (https://www.toukomst.nl/ideeen/l-o-p-p-e-r-s-u-m-m-u-m/), 'a country of rising

(https://www.toukomst.nl/ideeen/kustzone-die-meegroeit-met-de-zeespiegelstijging/ and https://www.toukomst.nl/ideeen/rijzend-land/) halting in a different location every month, executing parts of the mindblowmap in a collaborative process with the local community. Every year the circus returns to all communities to progress the realisation of the long-term future. This way a co-creative process engages people, at the same time gives them the opportunity to take the lead.

\subsubsection{Regaining Trust}

The combination of establishing a superb future that is capable of withstanding big disruptions and positions local communities as the leaders of the future, builds new trust in an uncertain environment. This is a purposely slow process of incrementally adding value. Slow but certain, as it prevents one-offs and a sole injection only. The way this is envisioned is that the local community becomes responsible, has their say about the budgets and investments and therefore will regain trust in the future, each other and, ultimately, in the government.

\subsubsection{The Groningen Framework}

By integrating applied theories and a practical application in the carousel, the Groningen framework (figure 16) gives both analytical insights about the current regime and points at the necessities for transformative pathways. The tension between muddling through and unsafe planning approaches becomes manifest. The more courageous the current decision-makers are the more peripheric solutions emerge in a travelling process. The more likely it is the current practice of muddling through planning can be replaced by unsafe planning approaches. 

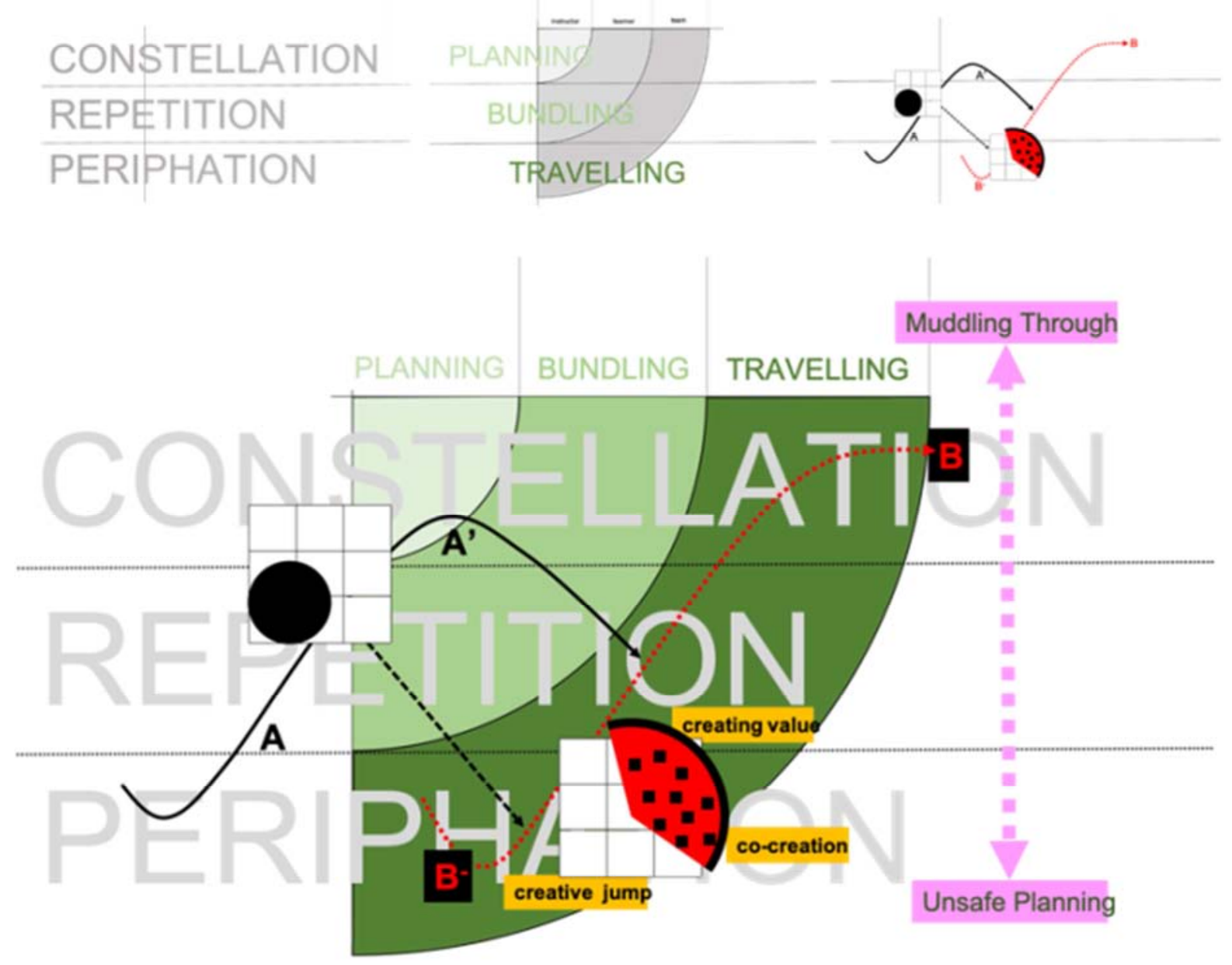

Figure 16. The Groningen framework for co-creative innovation.

\section{Conclusion}

The Groningen region is confronted with a range of unknown unknowns, such as a rising sea level, a series of earthquakes as a result of decades of gas extraction, and a shrinking population due to decreasing opportunities in job availability and education. An existing constellation of regional governments have tried for decades to turn the tide, muddling through, deciding on the best possible small step forward. This however has been undertaken incrementally relating the pace of adjustments to the acceptability amongst the population. This is no longer feasible as it will not offer any solace, as it led to loss of trust and support for the decisions taken by the government.

The Groningen analysis of policy propositions and submitted ideas by local people illustrates that the majority focuses on the shorter term not anticipating future uncertainties. Moreover, it shows that incremental policymaking leads to suboptimal spatial quality, degraded landscapes and increased risks at disruptions.

In this article an alternative framework how to enhance land-use transformability is presented. In this framework theoretical foundations of transformation, multilevel perspective and three level learning are brought together and show the current omissions of the prevailing system, but also propose a creative environment for establishing such transformations, which are much better capable of anticipating, responding to and dealing with an unprecedented future. Both the search for the most peripherical ideas and organising an inspirational process are needed to make this happen. This search for ideas and projects that are really transformational can only be supported with unsafe planning approaches, decision makers who have the courage to take risks and making use of local and regional natural conditions.

In this co-creative innovation process, it is essential to employ creativity, open-mindedness and out of the box thinking, because:

1. Innovative thinking for a novel future can only be deployed in an open creative environment;

2. It makes it possible to signal the hidden novelties that point towards this new future.

3. It is necessary for inventing novel solutions. Starting at the periphery of mind brings the extravaganza within reach and this is needed to initiate transformational thinking; 
4. It leads to transformational landscape(s).

5. It engages local communities to take their own future at hand and become responsible.

Imagine, some of these design-led results illuminate transformational agency. For instance, the design for the emergent landscape of the northern region gains adaptive capacity by allowing the land forming being driven by the intrinsic powers of the sea, which over time creates a new transformational landscape. Within this new context an alternative food provision for everyone living in the region can be achieved when a diet is adopted that stays within the planetary boundaries [35], feeds everyone with healthy food and gains a net value instead of claiming EU subsidies.

In order to be prepared for something that cannot be known, both the process as the content need to be brought beyond the obvious, where peripherical solutions are on a journey, travelling to a confident future.

\section{References}

[1] IPCC. Climate Change 2014: Impacts, Adaptation, and Vulnerability. Part A: Global and Sectoral Aspects. Contribution of Working Group II to the Fifth Assessment Report of the Intergovernmental Panel on Climate Change [Field, C. B., V. R. Barros, D. J. Dokken, K. J. Mach, M. D. Mastrandrea, T. E. Bilir, M. Chatterjee, K. L. Ebi, Y. O. Estrada R. C. Genova, B. Girma, E. S. Kissel, A. N. Levy, S. MacCracken, P. R. Mastrandrea, and L. L. White (eds.)]. Cambridge University Press, Cambridge, United Kingdom and New York, NY, USA. 2014; 1132 pp.

[2] Gu, D.; Gerland, P.; Pelletier, F.; Cohen, B. Risks of Exposure and Vulnerability to Natural Disasters at the City Level: A Global Overview. United Nations Department of Economic and Social Affairs, Population Division: New York, USA, 2015; Technical Paper No. 2015/2.

[3] Rosegrant, M. W.; Cline, S. A. Global food security: challenges and policies. Science 2003, 302, 5652, 1917-1919.

[4] Madhav, N.; Oppenheim, B.; Gallivan, M.; Mulembakani, P; Rubin, E.; Wolfe, N. Pandemics: Risks, Impacts, and Mitigation. In: Mental, Neurological, and Substance Use Disorders. Disease Control Priorities, $3^{\text {rd }}$ ed., volume 4; Patel, V., D. Chisholm., T. Dua, R. Laxminarayan, M. E., Medina-Mora, Eds.; World Bank: Washington, DC., USA, 2015; Volume 4: doi:10.1596/978-1-4648-0426-7. License: Creative Commons Attribution CC BY 3.0 IGO.

[5] Lindblom, C. E. The Science of "Muddling Through". Public Administration Review 19, 2 (Spring, 1959) pp. 79-88. Published by: Blackwell Publishing on behalf of the American Society for Public Administration.

[6] Roggema, R. Swarm Planning: The development of a Methodology to Deal with Climate Adaptation. PhD-thesis, Delft University of Technology and Wageningen University and Research Centre. Delft, Wageningen, 2 October 2012.

[7] Roggema, R. The use of spatial planning to increase the resilience for future turbulence in the spatial system of the Groningen region to deal with climate change. Proceedings UKSS-conference, Oxford, UK, 1-3 September 2008.

[8] Roggema, R.; Genel Altinkaya, Ö; Psarra, I. De Toukomst is al lang begonnen. Hanze University of Applied Sciences Groningen. Groningen, the Netherlands, 2020.

[9] Ten Hooven, M. No doom image but a green image (Geen doembeeld maar een groen beeld, in Dutch). Vrij Nederland $2020144,17-18$ 18-23.

[10] Batty, M. Building a science of cities. Cities 2012, 29 , Supplement https://doi.org/10.1016/j.cities.2011.11.008

S9-S16.

[11] Roggema, R;, Vermeend, T.; Van den Dobbelsteen, A. Incremental change, transition or transformation? Optimising change pathways for climate adaptation in spatial planning. Sustainability 2012, 4 2525-2549.

[12] Gunder, M. Fake it until you make it, and then... Planning Theory 2011, 10, 3 201-212.

[13] Davy B. Plan it without a condom! Planning Theory 2008, 7, 3 301-317.

[14] Miraftab, F. Insurgent planning: situating radical planning in the Global South. Planning Theory 2009, 8, $132-50$.

[15] Boelens, L. Theorizing practice and practising theory: outlines for an actor- relational - approach in planning. Planning Theory 2010, 9, $128-62$.

[16] Newman, S. Post-anarchism and space: Revolutionary fantasies and autonomous zones. Planning Theory 2011 10, 4 344-365.

[17] Chapin III, F. S.; McGuire, A. D.; Ruess, R. W.; Hollingsworth, T. N.; Mack, M. C.; Johnstone, J. F.; Kasischke, E. S.; Euskirchen, E. S.; Jones, J. B.; Jorgenson, M. T.; Kielland, K.; Kofinas, G. P.; Turetsky, M. R.; Yarie, J.; Lloyd, A. H.; Taylor, D. L. Resilience of Alaska's boreal forest to climatic change. Canadian Journal of Forest Research 2010, 40, doi: 10.1139/X10-074.

[18] Geels, F. W.; Kemp, R. Transitions, transformations and reproduction: Dynamics of socio-technical systems. In Flexibility and Stability in Economic Transformation; McKelvey, M., M. Holmén (Eds.). Oxford University Press: New York, USA, 2006, pp. 227-256.

[19] Gunderson, L.; C. S. Holling Panarchy: understanding transformations in human and natural systems;. Island Press: Washington DC, USA, 2002.

[20] Folke, C.; Carpenter, S. R.; Walker, B.; Scheffer, M.; Chapin, T.; Rockström, J. Resilience thinking: integrating resilience, adaptability and transformability. Ecology and Society 2010 15, $420 . \quad$ [online] URL: http://www.ecologyandsociety.org/vol15/iss4/art20/

[21] Perez, C. Technological Revolutions and Financial Capital. Edgar Elgar: Cheltenham, 2002.

[22] Ainsworth-Land, G. T. Grow or Die. The Unifying Principle of Transformation, Reissued Edition. John Wiley \& Sons: New York, Chichester, Brisbane, Toronto, Singapore, 1986.

[23] Geels, F. W. Technological transitions as evolutionary reconfiguration processes: a multilevel perspective and a case study. Research Policy 2002, 31, 1257-1274.

[24] Geels, F. W. Processes and patterns in transitions and system innovations: Refining the co-evolutionary multi-level perspective. Technological Forecasting \& Social Change 2005, 72, 681-696. 
[25] Geels, F. W. The multi-level perspective on sustainability transitions: Responses to seven criticisms. Environmental Innovation and Societal Transitions 2011 1, 24-40.

[26] Kemp, R.,; Rip, A.; Schot, J. W. Constructing transition paths through the management of niches. In Path Dependence and Creation; Garud, R., Karnoe, P. (Eds.) 269- 299. Lawrence Erlbaum: Mahwah, 2001.

[27] Geels, F. W.; Schot, J. Typology of sociotechnical transition pathways. Research policy 2007 36, 3 399-417.

[28] Van der Ploeg, J. D.; Boutna, J.; Rip, A.; Rijkenberg, F. H. J.; Ventura, F.; Wiskerke, J. S. C. On Regimes, Novelties, Niches and Co-Production. In Seeds of Transition. Essays on novelty production, niches and regimes in agriculture; Wiskerke, J. S. C., Van der Ploeg, J. D. (Eds.) Royal Van Gorcum: Assen, 2004.

[29] Vos, L. Innovations in Organisational and Community Learning. In The Design Charrette: Ways to Envision Sustainable Futures; Roggema, R. (Ed.) Springer: Dordrecht, Heidelberg, London: Springer, 2013.

[30] Homan, T. Teamleren: Theorie en facilitatie. Academic Service: Schoonhoven, 2001.
[31] Argyris, C.; Schön, D. Theory in practice. Jossey-Bass: San Francisco, 1974.

[32] Argyris, C.; Schön, D. Organizational learning. Addison-Wesley: Reading, 1978.

[33] Argyris, C. On organizational learning. Blackwell Publishers: Cambridge, 1992.

[34] Noordhoff, I.; Melief, M. Routekaart \#vrijetoukomst. Digitale special Noorderbreedte, September 2020. URL: https://noorderbreedte.nl/wp-content/uploads/2020/09/NB_To ukomst_Special-DEF.pdf (accessed on 20 September 2020).

[35] Willett, W.; Rockström J.; Loken, B.; Springmann, M.; Lang, T.; Vermeulen, S.; Garnett, T.; Tilman, D.; DeClerck, F.; Wood, A.; Jonell, M.; Clark, M.; Gorden, L. J.; Fanzo, J.; Hawkes, C.; Zurayk, R.; Rivera, J. A.; De Vries, W.; Sibanda, L. M.; Afshin, A.; Chaudhary, A.; Herrero, M.; Augustina, R.; Branca, F.; Lartey, A.; Fan, S.; Crona, B.; Fox, E.; Bignet, V.; Troell, M.; Lindahl, T.; Singh, S.; Cornell, S. E.; Srinath Reddy, K.; Naraïn, S.; Nishtar, S.; Murray, C. J. L. (2019) Food in the Anthropocene: the EAT-Lancet Commission on healthy diets from sustainable food systems. The Lancet Commissions 2019 393, 10170, 447-492. DOI: https://doi.org/10.1016/S0140-6736(18)31788-4. 